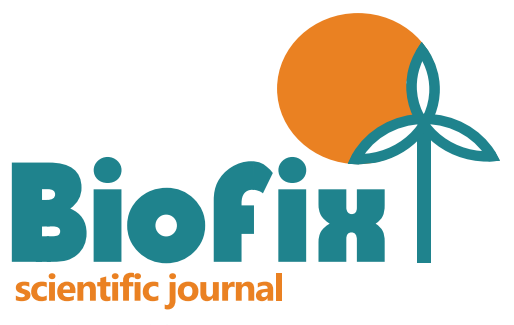

v. 2 n. 12017

\title{
EMISSÃO DE GASES DE EFEITO ESTUFA E PROPOSTA DE PROJETO PARA COMPENSAÇÃO: UM ESTUDO DE CASO E-COMMERCE
}

\author{
ESTIMATION OF GREENHOUSE GASES EMISSIONS AND PROPOSAL OF
} A PROJECT FOR COMPENSATION: E-COMMERCE A CASE STUDY

Recebido em 07/03/2017

Aceito em 29/05/2017

Publicado em 31/05/2017

DOI: dx.doi.org/10.5380/biofix.v2i1.51086

\author{
Christian Horst Nunnenkamp ${ }^{1}$ \\ Ana Paula Dalla Corte ${ }^{2}$
}

Universidade Federal do Paraná, Curitiba, Paraná, Brasil cnunnenkamp@gmail.com ${ }^{1}$ \& anapaulacorte@gmail.com ${ }^{2}$

\section{RESUMO}

O objetivo geral deste trabalho foi estimar a emissão de gases de efeito estufa (GEEs) de uma empresa de peças de decoração infantil e-commerce utilizando a metodologia GHG Protocol e propor um projeto de compensação ambiental. Foi criada uma metodologia para estimar as emissões do Escopo 3, considerando a posição geográfica do destinatário final para onde os produtos comercializados foram enviados. O estudo resultou em uma emissão total de $201,77 \mathrm{tCO}_{2 \mathrm{e}}$ e de $4,88 \mathrm{tCO}_{2}$ biogênico, no âmbito dos três escopos. O projeto de compensação baseou-se em sequestro de carbono, por meio de plantio florestal. Com base em um modelo existente com sete cenários de plantios, com o uso de espécies de Eucalyptus, seria necessário um maior número de mudas para absorver a mesma quantidade de GEEs, seguido das espécies nativas e de Pinus. Contudo, por conta de a região escolhida para o plantio ser diferente da região do modelo original, existe a possibilidade de que alguns cenários propostos não se desenvolvam conforme o esperado, devido, principalmente, às diferenças de clima e solo. Mesmo que o plantio florestal seja efetivo, é importante ressaltar que as árvores calculadas se referem somente ao ano base do levantamento, ou seja, novas árvores devem ser plantadas todos os anos para a devida compensação. A partir das análises dos objetivos, concluiuse que o trabalho em conjunto da redução com a mitigação das emissões através de plantio florestal é muito importante para o combate ao aumento da temperatura terrestre.

PALAVRAS-CHAVE: Dióxido de carbono, GHG Protocol, Inventário de emissões, Sequestro de carbono.

\section{ABSTRACT}

The aim of this study was to estimate the emission of greenhouse gases (GHGs) of an e-commerce decoration products company using the GHG Protocol methodology and propose an environmental compensation project. A methodology was created to estimate Scope 3 emissions, considering the geographical location of the destination where the commercialized products were sent. The study resulted in a total emission of $201.77 \mathrm{tCO}_{2 \mathrm{e}}$ and $4.88 \mathrm{tCO}_{2}$ biogenic under the three scopes. The compensation project was based on carbon sequestration through forest planting. Based on an existing model with seven planting scenarios, with the use of Eucalyptus species, a greater number of seedlings would be required to absorb the same amount of GHGs, followed by native and Pinus species. However, due to the region chosen for planting is different from the region of the original model, there is a possibility that some proposed scenarios do not develop as expected, mainly due to differences in climate and soil. Even if the forest plantation is effective, it is important to remind that the calculated trees refer only to the base year of the survey, i.e., new trees should be planted every year for appropriate compensation. From the analysis of the objectives, it was concluded that it is very important to reduce and to mitigate the emissions through forest planting to combat the increase in global temperature.

KEYWORDS: Carbon dioxide, GHG Protocol, Emission inventory, Carbon sequestration. 


\section{INTRODUÇÃO}

Nos últimos anos, o planeta Terra tem sofrido com mudanças no clima que têm afetado a todos. Essas mudanças são consequências do aumento na concentração de gases de efeito estufa (GEEs), sendo esses, dióxido de carbono $\left(\mathrm{CO}_{2}\right)$, metano $\left(\mathrm{CH}_{4}\right)$, óxido nitroso $\left(\mathrm{N}_{2} \mathrm{O}\right)$, alguns clorofluorcarbonos (CFC), dentre outros.

O inventário de emissões de GEEs é uma ferramenta para contabilizar as emissões de GEEs de uma empresa, grupo de empresas e governos (em todas suas esferas). São três as linhas metodológicas de inventário utilizadas internacionalmente, sendo elas: Intergovernmental Panel on Climate Change (IPCC), ISO 14.064 e GHG Protocol. O Greenhouse Gas Protocol Initiative (GHG) é a ferramenta mais comumente utilizada no âmbito empresarial, pois é oriunda de uma parceria entre diversas organizações não governamentais (ONGs), governos e outras entidades, reunidos pelo World Resources Institute (WRI) e o World Business Council for Sustainable Development (WBCSD) (SANQUETTA et al., 2013).

Lançado em 1998, o objetivo do GHG Protocol é desenvolver um padrão de contabilização e comunicação de GEEs aceito internacionalmente e promover sua adoção em larga escala (FLIZIKOWSKI, 2012). Dessa maneira, são oferecidas normas e diretrizes para outras organizações, para que possam seguir uma mesma padronização.

Em 2008, a ferramenta foi customizada para o Brasil pela Fundação Getúlio Vargas (FGV) e pelo World Ressources Institute (WRI) em parceria com o Ministério do Meio Ambiente (MMA), com o Conselho Empresarial Brasileiro para o Desenvolvimento Sustentável (CEBDS), com o World Business Council for Sustainable Development (WBSCD) e mais 27 empresas fundadoras. O Programa Brasileiro está fundamentado na metodologia do GHG Protocol, seguindo assim as mesmas diretrizes e princípios para a elaboração do inventário de emissões de GEEs. Existe também um apoio por parte do Programa para a realização do inventário nas empresas, tais como: a elaboração voluntária de emissões; a capacitação de empresas para melhor utilização da ferramenta; a divulgação em site na internet; e a troca de informações e modelos de gestão (disseminação do conhecimento) (FLIZIKOWSKI, 2012).

A compensação ambiental é uma iniciativa voluntária, visando compensar parcial ou totalmente as emissões de GEEs. O termo neutralização significa tornar as emissões totalmente neutras, seja por meio de remoção ou redução externa. De acordo com CONAR (2007), recomenda-se que seja utilizado o termo compensação, ao invés de neutralização, visto que tornar zero uma emissão de GEEs pode ser considerado um exagero, devido sua complexidade em zerar totalmente as emissões. A compensação por meio de plantios florestais é uma forma natural de sequestrar o gás carbônico pelos vegetais através da fotossíntese, fixando-o em forma de matéria lenhosa ou biomassa. O sequestro de carbono constitui o processo de crescimento dos vegetais, ou seja, quanto maior o porte da planta, mais biomassa se acumula e, consequentemente, maior é a quantidade de carbono fixada (CHANG, 2004).

Diferentemente do comércio tradicional, o ecommerce traz vantagens, como uma maior flexibilidade operacional com menor custo e o atendimento em tempo real, muitas vezes realizado através de redes sociais. 0 cenário do e-commerce no Brasil é favorável e espera-se que até 2018 seja responsável por 5\% do total de crescimento anual das vendas (SEBRAE, 2015). Mesmo com a grande expectativa de crescimento desse tipo de comércio, nota-se uma carência de estudos de caso de micro e pequenas empresas relacionados à temática de gestão coorporativa de carbono, fazendo que este estudo seja um dos primeiros com essas características.

Dessa forma, o presente estudo teve como objetivo realizar as estimativas das emissões diretas e indiretas de GEEs para uma empresa de peças de decoração infantil ecommerce, no âmbito dos três escopos propostos pelo GHG Protocol, e propor um projeto de compensação para a quantidade estimada de GEEs emitida pela empresa.

\section{MATERIAL E MÉTODOS}

\section{A empresa em estudo}

A empresa em estudo produz artigos e peças personalizados para a decoração de quarto infantil. Sendo uma empresa e-commerce que não exige a comunicação presencial, suas vendas conseguem abranger todo o território nacional e suas entregas são feitas pelos Correios.

\section{GHG Protocol}

Dentro dos limites e das diretrizes providos pelo GHG Protocol, para este trabalho os limites organizacionais foram considerados somente no controle operacional, por se tratar de uma microempresa. Os limites operacionais estabelecidos englobaram as emissões diretas e indiretas. Para este trabalho, o Brasil foi considerado como sendo 
limite geográfico e o ano-base para o levantamento de dados foi o de 2015. A empresa está sediada no município de Lorena, estado de São Paulo.

Com o fluxo de trabalho apresentado na Figura 1, é possível identificar as fontes de emissões em todas as etapas do processo, desde a aquisição das matérias-primas até a entrega do produto ao cliente.

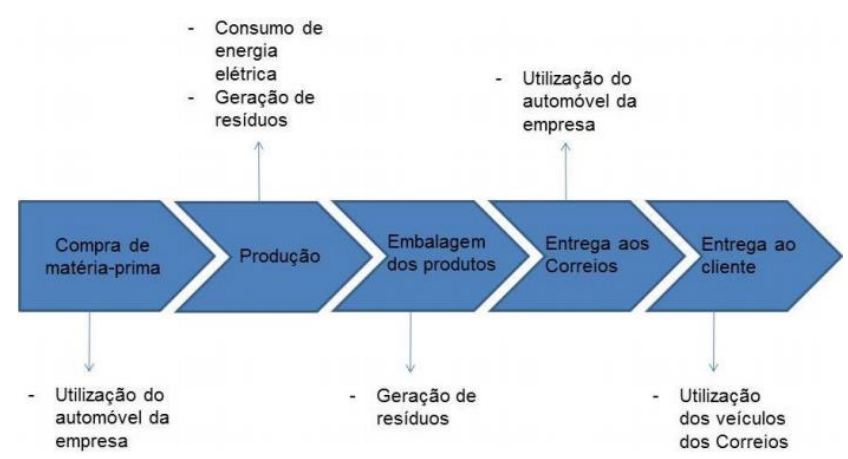

Figura 1. Fluxo de trabalho da empresa e-commerce em estudo.

A partir do fluxo de trabalho podem-se classificar as emissões nos três escopos, sendo eles:

- Escopo 1:

- Combustão móvel - veículo próprio; e

- Resíduos sólidos.

- Escopo 2:

- Compra de energia elétrica - equipamentos e processo.

- Escopo 3:

- Upstream - Viagens de ida e volta do trabalho de empregados; e

- Downstream - Transporte de produtos vendidos transporte pelo Correios.

O transporte dos produtos vendidos pela empresa é feito via Correios. É importante salientar que vários fatores são importantes para o cálculo das emissões, como: o trajeto realizado; os veículos utilizados pelos Correios; e os combustíveis utilizados nos veículos dos Correios. Porém, esses fatores não foram considerados, pois os dados não foram fornecidos por questões de segurança. Com isso, foi necessário estimar os dados utilizados nesse item. Foram usados os registros da empresa com o endereço para onde as encomendas foram enviadas, utilizando a agência dos Correios de Lorena como ponto de partida.

Neste estudo, não foram consideradas as emissões provenientes de efluentes líquidos e as emissões fugitivas de extintores e de ar-condicionado.

\section{Cálculo de emissões}

Para a quantificação das emissões, utilizou-se a ferramenta de cálculo do Programa Brasileiro GHG Protocol (versão 2016.1.1 de 18 de agosto de 2016). Foram utilizados os valores dos fatores de emissão e dos potenciais de aquecimento global definidos pela ferramenta.

A empresa estudada possui um automóvel tipo flex e utiliza gasolina como combustível. O levantamento de dados de quilometragem indica que em 2015 foram percorridos $5.100 \mathrm{~km}$. O consumo médio do automóvel sugerido pela ferramenta é de $12,2 \mathrm{~km} . \mathrm{L}^{-1}$. O consumo total foi obtido pela seguinte fórmula:

$$
C_{T}=\frac{D}{C_{m v}}
$$

Em que: $C_{T}=$ consumo total de combustível (L); $D=$ distância total percorrida $(\mathrm{km})$; e $C_{m v}=$ consumo médio do veículo $\left(\mathrm{km} \cdot \mathrm{L}^{-1}\right)$.

Por se tratar de uma empresa de confecção de artefatos têxteis, os resíduos gerados foram, em sua maioria, materiais provenientes da produção. A Tabela 1 apresenta os tipos de resíduos e suas respectivas quantidades. Para os cálculos para disposição dos resíduos em aterro sanitário, considerou-se para a cidade de Lorena/SP uma precipitação anual maior ou igual a $1.000 \mathrm{~mm}$.ano ${ }^{-1}$ (INMET, 2016) e uma temperatura anual média maior que $20^{\circ} \mathrm{C}$. No aterro, foi utilizado somente o método de cobertura, com ausência de compactação, de nivelamento do resíduo e de recuperação de metano.

Tabela 1. Quantidade de resíduos gerados pela empresa ecommerce

\begin{tabular}{cc} 
commerce & Quantidade (t) \\
\hline Papéis/papelão & 0,027 \\
Resíduos têxteis & 1,215 \\
Resíduos alimentares & 0,0675 \\
Outros materiais inertes & 0,0405 \\
\hline Total & $\mathbf{1 , 3 5}$ \\
\hline
\end{tabular}

Para o cálculo de emissões provenientes do consumo de energia elétrica, utilizaram-se os dados do consumo mensal do no ano-base, conforme mostrado na Tabela 2. No Escopo 3, o deslocamento dos funcionários (casatrabalho) foi enquadrado nas emissões Upstream, definido como: emissões indiretas relacionadas aos bens e serviços comprados ou adquiridos (PROGRAMA BRASILEIRO GHG Protocol, 2016). Para essa empresa, a quantidade de $\mathrm{CO}_{2 \mathrm{e}}$ 
emitida foi igual a zero, uma vez que os funcionários utilizam a bicicleta como meio de transporte.

Tabela 2. Quantidade de kWh energia elétrica consumida pela empresa e-commerce em 2015 (kWh)

Consumo de energia elétrica (kWh)

\begin{tabular}{llllllllllllll}
\hline \multicolumn{10}{c}{ Consumo de energia elétrica (kWh) } \\
\hline Jan & Fev & Mar & Abr & Mai & Jun & Jul & Ago & Set & Out & Nov & Dez \\
\hline 163 & 429 & 330 & 234 & 286 & 137 & 146 & 134 & 120 & 187 & 285 & 300 \\
\hline
\end{tabular}

No conceito de emissões Downstream, consideradas emissões indiretas relacionados aos bens e serviços vendidos (PROGRAMA BRASILEIRO GHG Protocol, 2016), enquadra-se o transporte de produtos vendidos. Uma estimativa dos dados foi realizada a partir de coleta de informações informais com funcionários dos Correios e também a partir de observações.

Para o transporte rodoviário, considerou-se um caminhão de porte médio a diesel, ano 2013 e com consumo médio de 5,3 km. $\mathrm{L}^{-1}$, como veículo utilizado pelos Correios. A metodologia empregada para a contabilização da distância percorrida foi dividida em duas partes, sendo elas: entrega direta e entrega indireta. A entrega direta considerou que o veículo rodoviário transporta diretamente o produto da empresa para o destino final (cliente). No ano de 2015, foram feitas 409 entregas diretas, com uma média de $383 \mathrm{~km}$ percorridos. Os requisitos para uma entrega ser classificada como direta, foram:

- Se o destinatário (cliente) se localiza no estado de São Paulo; e

- Se o destinatário (cliente) se localiza em algum estado vizinho ao de São Paulo, exceto Mato Grosso do Sul.

Assim, os estados de São Paulo, Rio de Janeiro, Minas Gerais e Paraná possibilitaram a entrega direta dos produtos. Por outro lado, o estado do Mato Grosso do Sul não se enquadrou nesse quesito, devido à maior distância.

A entrega indireta considerou que o percurso do produto foi realizado parte por transporte terrestre e parte por transporte aéreo. No ano de 2015, foram feitas 148 entregas indiretas, com uma média de 2,3 horas de voo. 0 requisito para uma entrega ser classificada como indireta foi:

- Se o destinatário (cliente) se localiza em algum estado que não tenha sido enquadrado para uma entrega direta.
As distâncias percorridas contabilizadas foram:

- A distância por transporte rodoviário da cidade de Lorena-SP até o Aeroporto Internacional de São Paulo Guarulhos;

- A distância por transporte aéreo do Aeroporto Internacional de São Paulo - Guarulhos até o aeroporto mais próximo do destino; e

- A distância por transporte terrestre do aeroporto mais próximo do destino até o destino final (cliente).

O Aeroporto Internacional de São Paulo - Guarulhos foi escolhido como aeroporto de origem, pois os Correios utilizam pela maior proximidade ao município de LorenaSP, sendo essa distância de $200 \mathrm{~km}$.

Para o transporte aéreo, foi identificada a empresa Rio Linhas Aéreas (CORREIOS, 2016), como prestadora de serviços de transporte de carga para os Correios. A partir de informações dos Correios, a empresa possui uma frota de aviões com as seguintes características: avião de carga do modelo Boeing 727 (AVIAÇÃO BRASIL, 2015).

Conforme exposto por Dittmer (2010), o consumo estimado de querosene de aviação dessa aeronave é de $4.536 \mathrm{~kg} / \mathrm{h}$ e sua capacidade de carga é de $8.618 \mathrm{~kg}$. A contabilização das horas de voo foi feita considerando a quantidade de horas que o avião leva do aeroporto de origem até o mais próximo do destino final. Para isso, foi utilizada a ferramenta Google Maps. O levantamento estimado da quantidade de horas de voo para o ano de 2015 foi de 106,45 horas.

A emissão estimada foi calculada por quilo de carga, utilizando o peso médio das encomendas enviadas pela empresa em estudo ( $5 \mathrm{~kg}$ ), que corresponde a 0,058\% do peso da capacidade de carga do avião. Por se tratar de um avião de carga, calculou-se então a emissão do peso correspondente das encomendas da empresa.

A emissão total de GEEs foi calculada por meio da somatória dos valores dos três escopos. As emissões de carbono biogênico foram expressas separadamente e, para o cálculo final de emissões, o carbono biogênico não foi avaliado, pois é considerado neutro por ser proveniente do ciclo biológico do carbono.

\section{Projeto de compensação proposto}

Foi proposto o plantio de floresta como projeto de compensação de emissões o sequestro de carbono. Assim, diferentes modelos foram propostos para que a empresa possa escolher o melhor de acordo com sua necessidade. Foram dois os tipos de modelos de plantios: a) floresta 
comercial, onde há a possibilidade de comercialização da madeira; e b) floresta nativa, para a recuperação ambiental de áreas degradadas. Nessa etapa, foram utilizados os cenários florestais criados por Flizikowski (2012) como base de cálculo, conforme apresentado na Tabela 3.

Tabela 3. Cenários para compensação de emissões de GEEs

\begin{tabular}{cccccc}
\hline Modelo & Espécie & Espaçamento & Anos & Área (ha) & Mudas \\
\hline A & Eucalyptus & $2,5 \mathrm{~m} \times 2,5 \mathrm{~m}$ & 7 & 818 & 1.242 .917 \\
B & Eucalyptus & $3,0 \mathrm{~m} \times 2,0 \mathrm{~m}$ & 7 & 797 & 1.211 .303 \\
C & Eucalyptus & $3,0 \mathrm{~m} \times 3,0 \mathrm{~m}$ & 7 & 1045 & 1.102 .282 \\
\hline D & Pinus & $2,5 \mathrm{~m} \times 2,5 \mathrm{~m}$ & 20 & 226 & 362.292 \\
E & Pinus & $3,0 \mathrm{~m} \times 2,0 \mathrm{~m}$ & 20 & 223 & 339.464 \\
F & Pinus & $3,0 \mathrm{~m} \times 3,0 \mathrm{~m}$ & 20 & 263,5 & 278.070 \\
G & Nativas & $3,0 \mathrm{~m} \times 2,0 \mathrm{~m}$ & 17 & 368 & $590.311,11$ \\
\hline
\end{tabular}

Fonte: Flizikowski (2012).

O modelo de espécies nativas refere-se ao levantamento estimativo de carbono fixado em plantios mistos em diferentes áreas do estado de São Paulo. A pesquisa realizada por Flizikowski (2012) apresentou uma emissão total de $119.174,21 \mathrm{tCO}_{2 \mathrm{e}}$, uma vez que o número de mudas e a quantidade total de emissões de GEEs foram identificados, calculou-se o fator de fixação de carbono para cada modelo (2).

$$
F_{f}=\frac{E_{t}}{N}
$$

Em que: $F_{f}=$ fator de fixação de carbono $\left(\mathrm{tCO}_{2 \mathrm{e}}\right.$ por muda); $E_{t}=$ emissão total $\left(\mathrm{tCO}_{2 \mathrm{e}}\right)$; e $N=$ número de mudas a serem plantadas.

\section{RESULTADOS E DISCUSSÃO}

\section{Quantificação de emissões}

Diante da baixa quantidade de empresas de mesmo porte e do mesmo ramo de atividade que realizam e disponibilizam publicamente inventários de emissões, encontrou-se dificuldade para comparar os resultados obtidos com trabalhos semelhantes. O principal deve-se a atuação das micro e pequenas empresas com enfoque no mercado interno, visando o seu crescimento. Dessa forma, seus investimentos não costumam ser direcionados à execução de inventários de GEEs. Outro motivo é a baixa cobrança de seus clientes para que a empresa atue com maior responsabilidade ambiental.

O consumo total de combustível do automóvel da empresa foi de 418,03 L em 2015. Com isso, as emissões totais de $\mathrm{CO}_{2 \mathrm{e}}$ e de $\mathrm{CO}_{2}$ biogênico foram de 0,71 t e 0,17 t, respectivamente. Nas emissões em $\mathrm{CO}_{2 \mathrm{e}}$ não são contabilizadas, as emissões de $\mathrm{CO}_{2}$ por combustão de biomassa foram contabilizadas como emissões de $\mathrm{CO}_{2}$ biogênico. As emissões de $\mathrm{CO}_{2}$ biogênico foram provenientes da porcentagem de etanol contida na gasolina utilizada pelo automóvel. As emissões dessa fonte são pequenas, quando comparadas as demais, e há alternativas para sua redução.

Fernandes (2015) mostrou que uma microempresa que presta serviços na área ambiental tem uma emissão maior proveniente de combustão móvel, equivalente a $5,78 \mathrm{tCO}_{2 \mathrm{e}}$. Assim, as diferentes atividades das empresas influenciam diretamente nas emissões, pois a microempresa de Fernandes (2015) utilizou muito mais a frota de veículos do que a empresa em estudo. Porém, mesmo que essas empresas atuem em segmentos diferentes, ainda há possibilidade para que ambas reduzam suas emissões, visto que essas emissões são diretas e as empresas têm controle sobre suas frotas de veículos.

Em 2015, a empresa em questão produziu em torno de 1,35 t de resíduos, que correspondem a 0,23 tC.tMSW ${ }^{-1}$ de Carbono Orgânico Degradável. Após a inserção de todos os dados na ferramenta de cálculo, obteve-se um total de $0,365 \mathrm{tCO}_{2 \text { e }}$ para 2015. Ao dividir a quantidade de resíduos gerada na empresa pelo número de cinco funcionários, a geração média per capita de resíduos resultante foi de 0,86 $\mathrm{Kg} . \mathrm{hab}^{-1} \cdot \mathrm{dia}^{-1}$, considerando 313 dias trabalhados. De acordo com ABRELPE (2014), o índice médio de geração de resíduos sólidos urbanos da população da região Sudeste é de 1,239 Kg.hab ${ }^{-1} \cdot$ dia $^{-1}$. Por conta da maior parcela de resíduos ser composta por resíduos têxteis, a empresa faz doações esporádicas para projetos comunitários existentes na cidade, diminuindo a de resíduos gerada.

Com os dados fornecidos pela empresa e os fatores de emissão de geração de energia elétrica do Sistema Interligado Nacional (SIN) gerou-se a Tabela 4, na qual consta que a empresa consumiu um total de $2.751 \mathrm{kWh}$, totalizando uma emissão de 0,34 $\mathrm{tCO}_{2 \mathrm{e}}$. Além disso, a variação do fator de emissão do SIN deve-se ao fato de a matriz energética brasileira ser baseada em energia hidráulica, isso faz com que haja uma variação sazonal nesses valores. Com isso, há também uma variação da quantidade de $\mathrm{CO}_{2}$ emitida.

$\mathrm{O}$ baixo consumo de energia elétrica no mês de janeiro deve-se ao mês de férias da empresa, e consequentemente, há menor consumo de energia elétrica. Em geral, o consumo dos equipamentos foi baixo, 
exceto pelo ar-condicionado e pelo compressor de ar utilizado para pintura. Durante os meses de julho a outubro, não houve a utilização do ar-condicionado, diminuindo consideravelmente o consumo de energia. $O$ compressor de ar foi utilizado conforme a demanda de produtos a serem pintados.

Tabela 4. Emissões provenientes da compra de energia elétrica

\begin{tabular}{cccc}
\hline $\begin{array}{c}\text { Mês } \\
\mathbf{( 2 0 1 5 )}\end{array}$ & $\begin{array}{c}\text { Quantidade } \\
\mathbf{( k W h )}\end{array}$ & $\begin{array}{c}\text { Fator de emissão } \\
\mathbf{( t C O}_{\mathbf{2}} \cdot \mathbf{M W h}^{-\mathbf{1}} \mathbf{)}\end{array}$ & $\begin{array}{c}\text { Emissão } \\
\left(\mathbf{t C O}_{\mathbf{2 e}} \mathbf{)}\right.\end{array}$ \\
\hline Janeiro & 163 & 0,1275 & 0,021 \\
\hline Fevereiro & 429 & 0,1321 & 0,057 \\
\hline Março & 330 & 0,1369 & 0,045 \\
\hline Abril & 234 & 0,1301 & 0,030 \\
\hline Maio & 286 & 0,1258 & 0,036 \\
\hline Junho & 137 & 0,1406 & 0,019 \\
\hline Julho & 146 & 0,1221 & 0,018 \\
\hline Agosto & 134 & 0,1183 & 0,016 \\
\hline Setembro & 120 & 0,1217 & 0,015 \\
\hline Outubro & 187 & 0,1180 & 0,022 \\
\hline Novembro & 285 & 0,1127 & 0,032 \\
\hline Dezembro & 300 & 0,1075 & 0,032 \\
\hline Total & $\mathbf{2 . 7 5 1}$ & - & $\mathbf{0 , 3 4 3}$ \\
\hline
\end{tabular}

A distância estimada percorrida pelo veículo rodoviário dos Correios foi de 155.032 km, totalizando um consumo de 27.684,29 L de diesel. Esse combustível consumido gerou uma emissão de 68,64 $\mathrm{tCO}_{2 \mathrm{e}}$ e 4,71 $\mathrm{tCO}_{2}$ biogênico. Considerando o tempo de voo estimado para o transporte das encomendas de $106,45 \mathrm{~h}$, o gasto de combustível de $4.536 \mathrm{~kg} \cdot \mathrm{h}^{-1}$ e a relação entre o peso médio das encomendas enviadas com a capacidade de carga do avião de $0,058 \%$, o consumo de combustível de avião para o transporte de uma encomenda foi de $280,14 \mathrm{~kg}$.

Assim, o consumo total de combustível para as 148 encomendas entregues no ano de 2015 foi de $41.461,40 \mathrm{~kg}$ de querosene de aviação. De acordo com BEN (2016), a densidade do querosene de aviação é de $0,799 \mathrm{~kg} . \mathrm{L}^{-1}$, o que resultou em um consumo de combustível do ano de 2015 de 51.891,61 L. Esse valor de combustível consumido correspondeu a uma emissão de $131,72 \mathrm{tCO}_{2 \mathrm{e}}$. A soma da quantidade de $\mathrm{CO}_{2}$ do transporte rodoviário com a do transporte aéreo totalizou 200,36 tCO2e. A quantidade final de $\mathrm{CO}_{2}$ biogênico foi de $4,71 \mathrm{t}$.

Para o cálculo final das emissões de $\mathrm{CO}_{2}$ da empresa em estudo, soma-se as emissões estimadas no âmbito dos três escopos, totalizando $201,77 \mathrm{tCO}_{2 \mathrm{e}}$ e 4,88 $\mathrm{tCO}_{2}$ biogênico. Na Figura $2 \mathrm{~A}$ consta o resumo das emissões totais de $\mathrm{CO}_{2 \mathrm{e}}$ e na Figura $2 \mathrm{~B}$ está o resumo das emissões totais de $\mathrm{CO}_{2}$ biogênico, dividas por escopo.
(A)

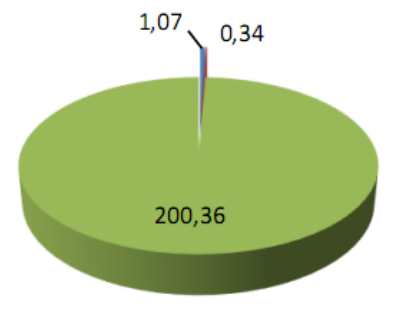

Escopo 1 Escopo 2 Escopo 3
(B)

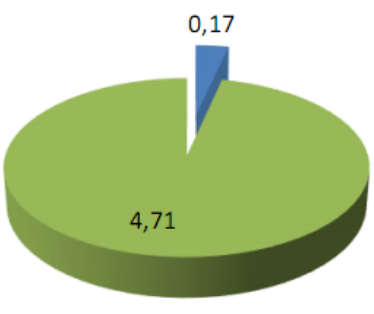

Figura 2. Emissão total ( $\mathrm{tCO}_{2 \mathrm{e}}$ ) por escopo setorial $(\mathrm{A}) \mathrm{e}$ biogênica $\left(\mathrm{tCO}_{2}\right)$ por escopo setorial (B).

Correspondendo a 99,3\% das emissões da empresa, foi evidente que o Escopo 3 teve o maior destaque das emissões, decorrentes do transporte de produtos vendidos, conforme mostra a Figura $2 \mathrm{~A}$. As emissões diretas do Escopo 1 corresponderam a aproximadamente $0,5 \%$ do total das emissões. A aquisição de energia elétrica teve a menor representatividade, com menos de $0,2 \%$ do total de emissões.

Na Figura 2B, o Escopo 3 também apresentou a maior representatividade, correspondendo a $96,53 \%$ das emissões de $\mathrm{CO}_{2}$ biogênico e o Escopo 1 com o restante de $3,47 \%$. Essas parcelas corresponderam às porcentagens de biocombustível e etanol contidas nos combustíveis utilizados pelos caminhões dos Correios e pelo automóvel da empresa, respectivamente. O Escopo 2 não possuiu nenhuma emissão de carbono biogênico, por se tratar apenas da compra de energia elétrica.

A partir dos resultados expostos na Figura 2, evidenciou-se que o transporte realizado pelos Correios representou a maior parcela de emissões da empresa, pois está constantemente presente na cadeia de comercialização do produto. Como essa atividade não é controlada pela empresa, não existem alternativas para reduzir essas emissões atualmente. Assim, quanto maior a comercialização dos produtos da empresa, maior será a emissão de GEEs provenientes dos serviços de translado dos produtos.

O levantamento de emissões realizado por Coelho e Qualharini (2010), em um departamento administrativo de engenharia, também apresentou uma maior emissão do Escopo 3, proveniente de viagens a negócios feitas de avião. Diferentemente da empresa em estudo, as emissões do Escopo 3 desse departamento administrativo são passíveis de redução, pois as mesmas estão sob regência do mesmo. Assim, o departamento buscou soluções para reduzir as emissões, como, por exemplo, com o aumento da utilização de videoconferências.

A ferramenta de cálculo do Programa Brasileiro GHG 
Protocol mostrou-se eficaz para este estudo de caso, pois todas as atividades da área de atuação da empresa se encaixaram nos escopos disponíveis pela ferramenta.

\section{Projeto de compensação utilizando plantios florestais}

A partir do levantamento de emissões de GEEs da empresa, foi possível estimar o número de árvores necessárias para compensar o impacto causado pelas emissões. Os fatores de fixação de carbono apresentados na Tabela 5 foram calculados com base no estudo desenvolvido por Flizikwoski (2012), conforme exposto na Tabela 3. O número de mudas a serem plantadas para este estudo considerou a quantidade de emissões totais estimadas de 201,77 tCO $\mathrm{CO}_{2}$. Esse valor não incluiu o $\mathrm{CO}_{2}$ biogênico. Com a quantidade total de emissões e com os fatores de fixação de carbono de cada modelo, foi possível calcular a quantidade de mudas a serem plantadas para cada modelo apresentado.

Tabela 5. Capacidade de absorção de carbono e número de mudas a serem plantadas e conduzidas por modelo

\begin{tabular}{ccc}
\hline Modelo & $\begin{array}{c}\text { Fator de fixação de carbono } \\
\text { (tCO }\end{array}$ por muda) & $\begin{array}{c}\text { Número de mudas a } \\
\text { serem plantadas }\end{array}$ \\
\hline A & 0,0958 & $2.106,40$ \\
B & 0,0983 & $2.052,80$ \\
C & 0,1080 & $1.868,10$ \\
D & 0,3286 & 614 \\
E & 0,3507 & 575,3 \\
F & 0,4282 & 471,2 \\
G & 0,2017 & $1.000,40$ \\
\hline
\end{tabular}

A maior vantagem de cultivar os gêneros Eucalyptus e Pinus deve-se ao fato de poder extrair e comercializar a madeira posteriormente. As florestas de espécies nativas têm sua aplicação voltada à restauração ambiental de uma determinada área ou região. Com os modelos propostos, a empresa pode escolher o cenário que mais se adeque ao seu objetivo, sendo ele comercial ou ambiental. Para essa escolha, deve-se considerar a quantidade de mudas a serem plantadas, os custos envolvidos no processo e o tempo de monitoramento.

De acordo com a Tabela 5, para se compensar a emissão total de 201,77 tCO 2 e são necessárias no mínimo 471 mudas de Pinus, plantadas com um espaçamento de 3,0 $\mathrm{m} \times 3,0 \mathrm{~m}$. Observou-se também que as espécies do gênero Pinus possuem a menor quantidade de mudas a serem plantadas do que as espécies nativas e de Eucalyptus. Como exposto por Flizikowski (2012), isso se deve ao tempo estabelecido para o crescimento de Pinus vinte anos, sendo superior ao dobro das espécies de Eucalyptus.

O programa Carbono Compensado LEPAC, apresentado por Rodacoski (2014), utilizou o fator de fixação de $0,2 \mathrm{tCO}_{2 \mathrm{e}}$ para espécies nativas. Esse fator de fixação tem um valor muito próximo ao Modelo G (Tabela 5). Essa proximidade de valores deve-se ao fato das espécies nativas de ambos os estudos pertencerem ao mesmo bioma de mata atlântica. Porém, é importante salientar que Rodacoski (2014) considerou um tempo de trinta anos de crescimento, sendo aproximadamente o dobro do tempo utilizado por Flizikowski (2012). Santos et al. (2010) obtiveram um fator de fixação de carbono inferior para espécies nativas do Cerradão em Palmas-TO, o que confirmou o exposto por Azevedo e Quintino (2010), de que o fator de fixação é dependente das diferenças de espécies, solo, clima e tipo de vegetação.

Os modelos A, B e C possuíram os menores fatores de fixação de carbono e, consequentemente, seria necessário plantar mais mudas para compensar a mesma quantidade de carbono emitida pela empresa. De acordo com Flizikowski (2012), o modelo apresenta limitações quanto à sua aplicação na esfera de tempo para que o carbono seja fixado pela floresta. Logo, o monitoramento pós-plantio é de suma importância para cumprir com o objetivo de compensar as emissões de GEEs.

May (2005) indicou alguns fatores que ameaçam seriamente o potencial efetivo de fixação de carbono, sendo eles: a escolha inadequada de espécies locais; a época do plantio; os ataques de pragas; e os problemas agronômicos, como ervas daninhas e doenças. Com isso, somente uma pequena porcentagem de mudas se desenvolve.

Flizikowski (2012) ressaltou que o modelo de compensação pode ser utilizado para qualquer bioma brasileiro, considerando que os fatores clima, solo e tipo de plantio influenciam diretamente no crescimento das espécies. Para o presente estudo, a região do Vale do Paraíba foi o local proposto para o plantio das espécies.

De acordo com o Anuário Estatístico ABRAF (2013), a região do estado de São Paulo possui 17,8\% da área nacional de florestas plantadas de Eucalyptus e Pinus. Conforme Carriello e Vicens (2011), a silvicultura de Eucalyptus domina grande parte da região, por conta das condições climáticas e de plantio mais favoráveis. Contudo, as florestas de Pinus têm maior área e distribuição na região Sul do país. Dessa forma, é possível que nem todos os modelos apresentados possam ser aplicados na região proposta para o plantio. 
Com isso, as espécies do gênero Eucalyptus e as nativas têm, nesse caso, preferência na escolha para o plantio de compensação, visto que há maior probabilidade de adaptação à região proposta para o plantio, diminuindo assim as perdas de mudas.

\section{Melhorias sugeridas para a gestão sustentável}

Seguem sugestões de iniciativas que poderiam melhorar o desempenho ambiental da empresa:

- Fazer o reaproveitamento de retalhos de tecido para criação de outros produtos, diminuindo a quantidade de resíduos;

- Fazer a troca de lâmpadas de halogênio por lâmpadas de LED;

- Fazer a troca de equipamentos por outros mais novos e mais eficientes;

- Dar preferência para a utilização de combustível proveniente de fontes renováveis no veículo da empresa, como o etanol, em substituição à gasolina;

- Melhorar a gestão do consumo de energia elétrica, buscando um consumo mais consciente, como por exemplo, desligando os equipamentos logo após o seu uso;

- Sistematizar uma rotina de armazenamento de dados para inventários futuros;

- Buscar por alternativas sustentáveis em projetos de expansão da empresa, como, por exemplo, construção civil;

- Buscar fornecedores que tenham maior preocupação ambiental e tenham uma gestão ambiental integrada aos negócios, e;

- Disponibilizar uma ferramenta de cálculos de emissões para os clientes e também disponibilizar um serviço de plantio de árvores para a compensação das emissões por encomenda específica. Com isso, o cliente teria a possibilidade de mitigar seus impactos no ato da comercialização dos produtos.

Com essas atitudes colocadas em prática, certamente haverá uma diminuição na quantidade de GEEs emitidas pela empresa e, também, haverá um maior envolvimento do cliente na cadeia de emissões, conscientizando-o da importância da compensação ambiental.

\section{CONCLUSÕES}

Diante dos resultados apresentados, percebe-se que o Escopo 3 possui uma grande relevância para empresas do tipo e-commerce nos moldes da empresa avaliada, devido a sua função na cadeia comercial.

A partir dos modelos propostos para compensação ambiental, a empresa pode escolher o modelo que mais se adequa a sua realidade. Porém, salienta-se que mais GEEs terão sido emitidos até a idade em que as árvores cultivadas possibilitem compensar a emissão de 2015. Portanto, as medidas para um desenvolvimento sustentável não devem ser restringidas apenas às medidas corretivas, mas também preventivas.

Uma observação e recomendação importante, para a compensação ambiental por meio do plantio de árvores, é necessário considerar as condições climáticas da região, para que sejam compatíveis com as espécies vegetais escolhidas, evitando, assim, perda da eficiência no crescimento das espécies.

\section{REFERÊNCIAS}

ABRELPE - Associação Brasileira de Empresas de Limpeza Pública e Resíduos Especiais. Panorama dos resíduos sólidos no Brasil. São Paulo: Grappa Editora e Comunicação, 2014. 120 p. Disponível em: <http://www.abrelpe.org.br/Panorama/ panorama2014.pdf>. Acesso em: 28/10/2016.

ABRAF - Associação Brasileira de Produtores de Florestas Plantadas. Anuário estatístico da ABRAF ano base 2012. Brasília: ABRAF, 2013. 148 p. Disponível em: <http://www.ipef.br/estatisticas/relatorios/anuario-ABRAF13BR.pdf>. Acesso em: 10/09/2016.

AVIAÇÃO BRASIL. Rio Linhas Aéreas (Brasil). 2015. Disponível em: <http://www.aviacaobrasil.com.br/rio_linhas_aereas_brasil>. Acesso em: 15/04/2017.

AZEVEDO, M. F. C.; QUINTINO, I. Manual Técnico: Um programa de compensação ambiental que neutraliza emissões de carbono através de projetos socioambientais de plantio de mudas nativas. Macaé-RJ: Ambiental Company, 2010.17 p.

BEN - Balanço Energético Nacional. Matriz energética nacional 2016 - ano base 2015. 2016. Disponível em: <https://ben.epe. gov.br>. Acesso em: 22/08/2016.

DITTMER, R. M. BOEING 727-200: airplane operations manual. 2010. 342 p. Disponível em: <http://www.aviationforall.com/wpcontent/uploads/2016/09/AOM_727_200_Sim_Copy.pdf>. Acesso em: 14/04/2017.

CARRIELLO, F.; VICENS, R. S. Silvicultura de eucalipto no vale do Paraíba do Sul/SP no período entre 1986 e 2010. In: Simpósio Brasileiro de Sensoriamento Remoto, 15., Curitiba, 2011. Anais... Curitiba, 2011. p. 6403-6409.

CHANG, M. Y. Sequestro florestal do carbono no Brasil dimensões políticas, socioeconômicas e ecológicas. São Paulo: Annablume, 2004. 280 p.

COELHO, G. J.; QUALHARINI, E. L. Neutralização dos gases de 
efeito estufa das atividades de um departamento administrativo de engenharia. In: Congresso Nacional de Excelência em Gestão, 6., Niteroi, 2010. Anais... Niteroi, 2010. p. 1-18. Disponível em: <http://www.inovarse.org/sites/default/files/T10_0244_1072.p df>. Acesso em: 27/10/2016.

CONAR - Conselho Nacional de Autorregulamentação Publicitária. Processo 232/07. 2007. Disponível em: $<$ http://conar.org.br/processos/detcaso. $p h p$ ?id=1736>. Acesso em: 09/04/2017.

CORREIOS. Correios recebe aprovação do Cade para participação acionária em empresa aérea. 2016. Disponível em: <https://www.correios.com.br/para-voce/noticias/correiosrecebe-aprovacao-do-cade-para-participacao-acionaria-emempresa-aerea>. Acesso em: 23/08/2016.

FERNANDES, C. R. Inventário e propostas de redução de emissões de gases de efeito estufa da empresa SS Ambiental, no ano base 2014 - Brusque/SC. 36 f. 2015. Monografia (Especialização em Projetos Sustentáveis, Mudanças Climáticas e Gestão Corporativa de Carbono) - Programa de Educação Continuada em Ciências Agrárias, Universidade Federal do Paraná, Curitiba, 2015.

FLIZIKOWSKI, L. C. Estimativa de emissões de dióxido de carbono na construção civil e neutralização com espécies florestais: um estudo de caso. 132 f. 2012. Dissertação (Mestrado em Engenharia Florestal) - Pós-Graduação em Engenharia Florestal, Universidade Federal do Paraná, Curitiba, 2012.

GHG Protocol. Metodologia do GHG Protocol da Agricultura. WRI Brasil e UNICAMP, 2016. 54 p. Disponivel em: <http://www.ghgprotocol.org/sites/default/files/ghgp/standard s_supporting/Metodologia.pdf>. Acesso em: 26/08/2016.

INMET - Instituto Nacional de Meteorologia. Normal Climatológica do Brasil 1961-1990. 2016. Disponível em: <http://www.inmet.gov.br/portal/index.php?r=clima/normaisCli matologicas $>$. Acesso em: 21/08/2016.

MAY, P. H.; BOHRER, C. B.; TANIZAKI, K.; DUBOIS, J. C. L.; LANDI, M. P. M.; CAMPAGNANI, S.; OLIVEIRA NETO, S. N.; VINHA, V. G. Sistemas agroflorestais e reflorestamento para captura de carbono e geração de renda. In: Encontro da Sociedade Brasileira de Economia Ecológica - ECOECO, 6., Brasília, 2005. Anais... Brasília, 2005. p. 1-33. Disponível em: <http://www.ecoeco.org.br/conteudo/publicacoes/encontros/vi _en/artigos/mesa2/Sistemas_Agroflorestais_e_Carbono.pdf $>$. Acesso em: 28/10/2016.

NUNNENKAMP, C. H. Estimativa de emissão de gases de efeito estufa e proposta para compensação: um estudo de caso. $53 \mathrm{f}$. 2017. Monografia (Especialização em Projetos Sustentáveis, Mudanças Climáticas e Gestão Corporativa de Carbono) Programa de Educação Continuada em Ciências Agrárias, Universidade Federal do Paraná, Curitiba, 2017.

PROGRAMA BRASILEIRO GHG Protocol. 2016. Disponível em: <http://www.ghgprotocolbrasil.com.br>. Acesso em 15/08/2016.

RODACOSKI, J. L.; ANDRADE, C. F. S. Cálculos e análises para o plantio de árvores na compensação das emissões de gases do efeito estufa emitido pelo gado. Revista Ambiência, v. 10, n. 2, p.
633-645, 2014.

SANQUETTA, C. R.; FLIZIKOWSKI, L. C.; CORTE, A. P. D.; MOGNON, F.; MAAS, G. C. B. Estimativa das emissões de gases de efeito estufa em uma obra de construção civil com a metodologia GHG Protocol. Enciclopédia Biosfera, v. 9, n. 16, p. 1088-1106, 2013.

SANTOS, D. R. R.; PICANÇO, A. P.; MACIEL, G. F.; SERRA, J. C. V. Estudo de neutralização dos gases de efeito estufa da Universidade Federal do Tocantins - reitoria e campus universitário de Palmas: uma forma de mitigação ambiental. Revista Geográfica Acadêmica, v. 4, n. 2, p. 29-40, 2010.

SEBRAE - Serviço Brasileiro de Apoio às Micro e Pequenas Empresas. Fique por dentro das perspectivas e tendências para o e-commerce. 2015. Disponível em: <http://www.sebrae.com. $\mathrm{br} /$ sites/PortalSebrae/artigos/fique-por-dentro-das-perspectivas -e-tendencias-para-o-e-commerce,05086a2bd9ded410VgnVCM1 000003b74010aRCRD>. Acesso em: 02/04/2017. 